Journal of Accident and Emergency Medicine 1995 12, 132-133

\title{
Changing standards for thrombolysis in accident and emergency departments
}

\author{
N. ZOLTIE' \& G. ROBERTSON²
}

'Accident and Emergency Department and 'Medical Audit Department, St James's University Hospital, Leeds, UK

\section{INTRODUCTION}

Thrombolysis has been recommended for all patients with acute myocardial infarction presenting within $6 \mathrm{~h}$ of the onset of pain. ${ }^{1}$ Compliance with this standard could be used as a measure of performance for an accident and emergency (A\&E) department. We here present the results of an internal audit of thrombolysis and discuss how diagnostic accuracy can seriously affect the ability to comply with differing standards for thrombolysis.

Key words: accident and emergency, acute myocardial imfarction, audit, standards, thrombolysis

\section{PATIENTS AND METHODS}

We audited all patients who were admitted to hospital after presenting to the A\&E department with chest pain in the period between January and March 1992. During this period, the A\&E doctors were encouraged to specify a diagnosis prior to admission. Five categories were suggested: definite myocardial infarction (AMI); possible myocardial infarction (?AMI); definite ischaemic heart disease (IHD); possible ischaemic heart disease (?IHD); and any other cause (other).

The eventual diagnoses (infarction or no infarction) were obtained from the discharge summaries, and the use of thrombolysis was noted. No further attempt was made to verify the criteria upon which the final diagnoses were made. The A\&E diagnosis on admission (in over $90 \%$ of cases made by a Senior House Officer) was compared with the final diagnosis at discharge.

\section{N. Zoltie,}

Consultant, Accident and Emergency Department, The General Infirmary at Leeds, Great George St, Leeds, LSI 3EX, UK

\section{RESULTS}

During the study period, a total of 312 patients were admitted after presenting with chest pain. In 24 instances the case notes could not be retrieved, and in 71 cases the diagnosis was non-cardiac. A total of 217 cases were left for analysis, of which
58 patients $(27 \%)$ proved on discharge to have had true AMI, while $159(73 \%)$ patients showed no evidence of AMI by the time of discharge.

Table 1 shows a comparison of the original A\&E admission diagnosis with the final diagnosis of infarction or no infarction. The numbers of patients actually receiving thrombolysis treatment are shown in parentheses for each group.

If the standard is set that all definite AMIs should have received thrombolysis treatment, then 15 patients would have been correctly thrombolysed (14 patients actually were), three patients would have been unnecessarily thrombolysed (none actually were), and 43 patients with true AMI would have been missed (17 actually received thrombolysis). If the standard is extended to include all definite and all suspected AMIs, then 34 patients should have been correctly thrombolysed (23 patients actually were), 46 patients would be unnecessarily thrombolysed (none actually were), and 24 patients would have been missed (eight actually received thrombolysis). Two patients who received thombolysis should not have done so by either standard. If the standards had been complied with, a change from 'all AMIs' to 'all definite and all suspected AMIs' would have resulted in an extra 19 patients receiving

Table 1. Initial diagnosis vs. final diagnosis (number of patients actually thrombolysed is shown in parentheses)

\begin{tabular}{lrr}
\hline \multirow{2}{*}{$\begin{array}{l}\text { A\&E department } \\
\text { diagnosis }\end{array}$} & \multicolumn{2}{c}{ Final diagnosis } \\
\cline { 2 - 3 } & \multicolumn{1}{c}{ AMI } & Not AMI \\
\hline AMI & $15(14)$ & $3(0)$ \\
?AMI & $19(9)$ & $43(0)$ \\
IHD & $4(1)$ & $32(2)$ \\
?IHD & $5(0)$ & $24(0)$ \\
Other & $15(7)$ & $57(0)$ \\
Total & $58(31)$ & $159(2)$ \\
\hline
\end{tabular}

AMI, acute myocardial infarction; IHD, ischaemic heart disease. 
N. Zoltie \&

G. Robertson thrombolysis treatment who should have done so, but at the expense of 43 patients who were thrombolysed unnecessarily.

\section{DISCUSSION}

Thrombolysis of all infarctions is an unrealistic target. ${ }^{1}$ The original work on thrombolysis included only $2 \%$ of cases with a normal ECG, ${ }^{2}$ but in an A\&E department up to $75 \%$ of chest pain cases are not the result of infarction.' The benefits of thrombolysis to patients with infarction are clearly defined, ${ }^{2.3}$ but the risks to people with no cardiac event have not been as clearly established. The benefit to the 19 patients who were correctly thrombolysed is a decrease in mortality from $13 \%$ to $11 \% .^{2,3}$ Set against this are the risks to the 43 patients who were unnecessarily thrombolysed. The incidence of severe bleeding and complications in infarction is $0.6 \%$, with minor complications in a further $11-17 \%{ }^{2}$ The incidence, severity and acceptability of complications in noninfarcting patients has been insufficiently quantified.

It is apparent from our audit that neither suggested standard was being adhered to accurately, and clinical steps have been taken to improve this situation. The obvious requirement is to improve our early diagnosis of infarction in order to allow more accurate targeting of thrombolysis. 'Fast-track' systems have been suggested to improve thrombolysis rates, ${ }^{4}$ but these still rely on the initial recognition and diagnosis in the A\&E department.

It is therefore apparent that, without knowledge of the diagnostic accuracy in the A\&E department, realistic targets for thrombolysis are difficult to justify on a rational basis. The standards for thrombolysis need to be carefully thought out on the basis of local information, and may depend on the case mix and admission criteria for individual departments. Statements such as 'all patients without contraindications to thrombolysis who present with ST-segment elevation or bundle branch block up to $12 \mathrm{~h}$ after the onset of symptoms should be treated, ${ }^{5}$ are the standard to be aspired to, but this does not equate to all AMIs, especially in an A\&E setting. National standards as criteria for audit may not always be appropriate if the false-positive and false-negative diagnostic rates differ from the norm.

\section{REFERENCES}

1. Hampton J.R. \& McWilliam A. (1992) Purchasing care for patients with acute myocardial infarction. Quality in Health Care 1, 68-73.

2. ISIS2 (Second International Study of Infarct Survival) Collaborative Group (1988) Randomised trial of intravenous streptokinase, oral aspirin, both, or neither among 17187 cases of suspected acute myocardial infarction: ISIS2. Lancet ii, 349-360.

3. Gruppo Italiano per lo Studio della Streptochinasi nell'Infarto Miocardico (GISSI) (1986) Effectiveness of intravenous thrombolytic treatment in acute myocardial infarction. Lancet $i, 397-402$.

4. Pell A.C.H., Miller H.C., Robertson C.E. \& Fox K.A.A. (1992) Effect of 'fast track' admission for acute myocardial infarction on delay to thrombolysis. British Medical Journal 304, 83-87.

5. Cobbe S.M. (1994) Thrombolysis in myocardial infarction. British Medical Journal 308, 216-217. 